\title{
Legal, normativo e responsivo: frames no debate sobre a reforma dos Tribunais de Contas brasileiros
}

\author{
Bruno Batista de Carvalho Luz 12 \\ Edson Ronaldo Guarido Filho ${ }^{3} 4$ \\ Marcos de Moraes Sousa 25 \\ 1 Universidade de Brasília / Programa de Pós-Graduação em Administração, Brasília / DF - Brasil \\ 2 Universidade Federal de Goiás / Programa de Pós-Graduação em Administração, Goiânia / GO - Brasil \\ 3 Universidade Positivo / Programa de Pós-Graduação em Administração, Curitiba / PR - Brasil \\ ${ }^{4}$ Universidade Federal do Paraná / Programa de Pós-Graduação em Gestão da Informação, Curitiba / PR - Brasil \\ ${ }^{5}$ Instituto Federal Goiano, Ceres / GO - Brasil
}

\begin{abstract}
Esta pesquisa teve como objetivo descrever os frames (enquadramentos) associados ao processo de mobilização em torno do debate sobre a reforma dos Tribunais de Contas brasileiros (TCs) no período de 2000 a 2017. Por meio de legitimacy accounts (assertivas de legitimidade) de atores legais e não legais foram identificados três frames: legal, associado à regulação, ressignificação e conformidade legal dos TCs; normativo, relacionado à transição da gestão política à competência técnica dos TCs e; responsivo, ligado à visibilidade social dos TCs. Os dados analisados consideraram discursos parlamentares, audiências públicas, debates, notícias e entrevistas com representantes de segmentos específicos como corporações profissionais, mídia, academia e sociedade civil organizada. Os achados lançam luz sobre a natureza processual da legitimidade em organizações institucionalizadas, como é o caso dos TCs, e destacam: a emergência das corporações profissionais enquanto entes mobilizadores das três esferas de segmentação; o surgimento de tônica cerimonialista em aspectos fomentadores do comportamento interoganizacional e; o aumento progressivo da responsividade ligada ao campo como decorrência do ingresso de segmentos específicos da sociedade no debate. Os resultados aprofundam a natureza político-discursiva da mudança institucional.
\end{abstract}

Palavras-chave: legalidade; legitimidade; frames; tribunais de contas; administração pública.

\section{Legal, normativo y responsivo: frames en el debate sobre la reforma de los tribunales de cuentas brasileños}

Esta investigación describe los marcos (frames) asociados al proceso de movilización en torno al debate sobre la reforma de los tribunales de cuentas (TC) brasileños en el período de 2000 a 2017. A través de los relatos de legitimidad de los actores legales y no legales, se identificaron tres marcos: legal, asociado a la regulación, resignificación y cumplimiento legal de los TC; normativo, asociado a la transición de la gestión política a la competencia técnica de los TC; y responsivo, asociado a la visibilidad social de los TC. Para el análisis de los datos se consideraron los discursos parlamentarios, audiencias públicas, debates, noticias y entrevistas con representantes de segmentos específicos, como corporaciones profesionales, medios de comunicación, academia y sociedad civil organizada. Las conclusiones arrojan luz sobre la dimensión procesal de la legitimidad en los tribunales y ponen de relieve: el surgimiento de las corporaciones profesionales como movilizadoras de las tres esferas de la segmentación; la aparición de un tono ceremonial en aspectos que fomentan el comportamiento interoganizacional y el aumento progresivo de la capacidad de respuesta vinculada al campo como resultado de la entrada de segmentos específicos de la sociedad en el debate. Los resultados profundizan el carácter político-discursivo del cambio institucional.

Palabras clave: legalidad; legitimidad; frames; tribunales de cuentas; administración pública. 


\section{Legal, normative, and responsive: frames in the debate about the reform of Brazilian Courts of Accounts}

This research describes the frames associated with the mobilization process around the debate about the reform of Brazilian Courts of Accounts (TCs) from 2000 to 2017. Through legitimacy accounts of legal and non-legal actors, three frames were identified: legal, associated with regulation, reframing, and legal compliance of TCs; normative, associated with the transition from political management to the technical competence of TCs and; responsive, associated with the social visibility of TCs. The data consisted of parliamentary speeches, public hearings, debates, news broadcasts, and interviews with representatives of specific segments such as professional corporations, media, academia, and organized civil society. The findings shed light on the procedural dimension of legitimacy in Justice organizations and highlight the emergence of professional corporations as mobilizing entities in the three spheres of segmentation; the emergence of a ceremonial tonic in aspects that promote inter-organizational behavior, and; the progressive increase in responsiveness linked to the field as a result of the entry of specific segments of society in the debate. The results deepen the political-discursive nature of institutional change.

Keywords: legality; legitimacy; frames; courts of accounts; public administration.

\section{INTRODUÇÃO}

O contexto que alicerça as relações em nível de sociedade, em grande medida, reproduz-se de forma mediada pela apreensão do conceito de legitimidade, cenário em que alguns grupamentos de entidades emergem. Este é o caso das organizações institucionalizadas (Guarido, Luz \& Silveira, 2018), em razão da relevância perante os contextos social e institucional do ordenamento estatal e pelo impacto sobre questões da vida em sociedade, como o respeito às leis, a coesão social e o desenvolvimento econômico (Guimaraes, Gomes \& Guarido, 2018). A partir desse recorte, este estudo foi voltado para o contexto das Entidades de Fiscalização Superior (EFS), organizações responsáveis pelo exercício do controle democrático sobre a aplicação dos recursos públicos que, na realidade brasileira, são conhecidas como Tribunais de Contas (TCs).

No tocantes às EFS, registra-se que essas organizações são históricas e que, em comparação aos poderes constitucionais, já transitaram pelos mais diversos contextos políticos e administrativos sem sofrer muitos danos (Speck, 2000). No Brasil, os TCs, embora muito próximos ao Poder Legislativo, apresentam autonomia e independência em relação aos demais poderes, atuando em grande medida por meio de mecanismos de decisão e sanção próprios (Willeman, 2017) e se estruturando em 33 tribunais, independentes entre si, com responsabilidade de controle externo sobre a aplicação de recursos públicos nas três esferas da federação.

Ocorre que os contornos institucionais associados a essas organizações, embora definidos constitucionalmente, têm-se apresentado na prática sob certa complexidade, constituindo-se enquanto espaço ambíguo, político e gerador de disputas narrativas entre diferentes grupos. Ilustram esse ponto, por exemplo, imagens discursivas dos TCs enquanto entidades assemelhadas aos órgãos de justiça, mobilizações de ideias por maior inserção técnica nos processos de controle externo e vocalizações pela democratização dos espaços de controle. Dessa forma, é da imprecisão das fronteiras acerca do exercício das práticas de controle, ou mesmo da multiplicidade de representações sociais sobre a figura dos TCs, que deriva o encadeamento de atos de contestação e validação da legitimidade dessas organizações.

Ao lado dessa questão, ainda sobre o contexto nacional, embora os TCs tenham sido valorizados com a Constituição Federal de 1988 (CF/88), em decorrência da introdução de variáveis ligadas 
ao exercício do controle social e ao desempenho governamental (Loureiro, Teixeira \& Moraes, 2009; Speck, 2000), nos últimos anos, essas organizações têm sido associadas a debates sobre o envolvimento em casos de corrupção, o alcance do poder jurisdicional de controle, a padronização nacional do processo de controle externo e a extinção de tribunais, conforme noticiado na mídia e em veículos especializados (Abraham, 2016; Araújo, 2017; G1, 2017; G1 CE, 2017a, 2017b; O Globo, 2017; Oliveira, 2008; Viana, 2017). A profusão de enunciados e argumentos em torno dessas temáticas constituem um campo de diálogo e discussão sobre a necessidade de reforma dessas organizações (Luz, Sousa \& Guarido, 2019) a partir de questões como configuração institucional (Lino \& Aquino, 2018), politização da atuação (Arantes, Abrúcio \& Teixeira, 2005), permeabilidade social (Rocha, Zucollotto \& Teixeira, 2020), desenho de más práticas (Lino \& Aquino, 2020), mecanismos de compliance (Azevedo \& Lino 2018) e elementos processuais (Rocha, 2013), que condicionam a legitimidade dos TCs à avaliação social.

Somam-se ao espaço dialógico mencionado os elementos contextuais que dão contorno e embasam a discussão no tocante à reforma dos TCs e que, dessa forma, merecem ser considerados nesse estudo: a crise de legitimidade dos TCs nos anos 2000, enquanto fenômeno político expressivo de contestação e crítica social; a edição das Leis de Responsabilidade Fiscal e da Ficha Limpa, enquanto fenômeno legal de repercussão extensiva aos TCs; a reforma do Poder Judiciário, como fenômeno de referência para a arquitetura de governança associada aos TCs; a deflagração da Operação Lava-Jato, enquanto mecanismo de expressão cultural acerca do combate à corrupção e; as manifestações ocorridas em 2013, enquanto elemento responsivo relacionado ao aumento da participação social nos debates da esfera pública (Luz et al., 2019).

A convergência discursiva mencionada, portanto, revela-se importante na medida em que, enquanto campo de debates, abre espaço para vozes de atores diversos, sinaliza para a possibilidade de captura de aspectos legais, normativos e responsivos e oferta espaço fértil para o uso de mecanismos como legitimacy accounts, compreendidos como esforços discursivos mobilizadores da legitimidade organizacional (Ashforth \& Gibbs, 1990; Sheridan \& Mote, 2017), e estratégias de framing, identificadas como elementos discursivos de significação, enquadramento e mobilização da ação coletiva (Benford \& Snow, 2000; Creed, Maureen \& Austin, 2002).

Assim sendo, os aspectos discutidos aqui elencam contribuições no campo teórico à medida em que buscam, por meio dos aspectos discursivos capturados, empreender olhar de base cultural e processual quanto à legitimidade de organizações institucionalizadas, como os TCs, e considerar aspectos de contorno legal, normativo e responsivo no contexto do fenômeno. Sob outra via, registram-se também contribuições de natureza empírica, uma vez que o uso de legitimacy accounts e frames na análise da mobilização discursiva em torno da reforma destacou: a emergência das corporações profissionais enquanto entes mobilizadores das três esferas de segmentação analítica; o surgimento de tônica cerimonialista em torno de aspectos ligados à mudança de comportamento interorganizacional; e o crescimento progressivo da responsividade associada ao campo em decorrência do ingresso de segmentos específicos da sociedade no debate.

Diante do contexto apresentado, o estudo teve como objetivo descrever, por meio de legitimacy accounts de atores legais e não legais, os frames associados ao processo de mobilização em torno do debate sobre a reforma dos TCs brasileiros no período de 2000 a 2017. Para tanto, abordou-se inicialmente o desenho teórico que fundamenta o estudo. Em seguida, pontuaram-se metodologicamente os procedimentos realizados. Após, discutiu-se o processo de mobilização em 
torno da reforma a partir de três frames: legal, normativo e responsivo. Por fim, apresentaram-se recomendações para exploração em trabalhos futuros.

\section{LEGALIDADE, LEGITIMIDADE E FRAMES}

Este trabalho se fundamenta na noção de legitimidade amparada pela relação entre institucionalismo organizacional e estudos sociolegais. Desse modo, o quadro teórico de sustentação apresentou dois focos de argumentação: a. o primeiro ligado aos conceitos de ambiente legal, campo legal e agência, uma vez que se pretende compreender o debate em torno da reforma dos TCs sob o prisma da articulação de atores na intersecção dos campos organizacional e legal e; b. o segundo voltado para os mecanismos de legitimacy accounts e frames, tendo em vista o componente discursivo associado ao objeto de estudo.

a. No tocante às noções de ambiente legal, campo legal e agência, ao deslocar o raciocínio institucional focado no ambiente institucional para a ótica legal, ressalta-se que, a aproximação entre estudos organizacionais e sociolegais (Edelman \& Suchman, 1997; Scott, 1994) revelou a existência de um ambiente legal (Edelman, 1992) voltado para a constituição e a formatação de regras sobre legalidade, espaço que tem sido historicamente negligenciado pelos estudiosos de organizações (Greenwood, Oliver, Sahlin \& Suddaby, 2008). Assim, esse ambiente legal das organizações pode ser compreendido como "arena na qual as organizações constroem coletivamente o significado da compliance" (Edelman, Leachman \& McAdam, 2010, p. 656), por meio de normas e práticas de conteúdo legal que se difundem no campo organizacional (Edelman, Fuller \& Mara-Drita, 2001).

Quanto à noção de ambiente legal, o recorte analítico de campo organizacional salienta perspectiva meso de análise (Kluttz \& Fligstein, 2016) que DiMaggio e Powell (1983, p. 76) inauguram como "área reconhecida da vida institucional". Ao traçar paralelo com os estudos legais, abre-se espaço para a noção de campo legal, compreendido pelo conjunto de "tribunais, legislaturas, agências administrativas, academia jurídica e todos os atores jurídicos, bem como as diversas partes que entram no sistema jurídico de forma ocasional" (Edelman, Krieger, Eliason, Albiston \& Mellema, 2011, p. 900). A principal diferença entre os dois campos residiria na lógica de eficiência e racionalização, presente nos campos organizacionais, adiante da lógica de regras e direitos, integrante dos campos legais (Edelman et al., 2010).

Ademais, um ponto importante na discussão sobre instituições e campos organizacionais é o conceito de agência enquanto "capacidade do ator de ter algum efeito no mundo social - alterando as regras, laços relacionais, ou distribuição de recursos” (Scott, 2008, p. 77). Tal mecanismo proporciona abertura para análise do poder de determinados agentes na interpretação, na mobilização e na condução de processos de mudanças institucionais. Nos estudos legais, cenário de inserção do objeto de análise deste artigo, a perspectiva agêntica poderia ser vislumbrada, por exemplo, na atuação das corporações profissionais em contextos de mudança legal a partir de processos de formação de consciência jurídica gerencializada, de enquadramento de argumentos legais no tocante à atuação de atores organizacionais e de deferência judicial às construções organizacionais da lei (Edelman, 2016).

b. Em relação à discussão de legitimacy accounts (assertivas de legitimidade) e frames (enquadramentos), ancorada no componente organizacional destaca-se que a legitimidade parte da compreensão da aceitação e da credibilidade como recursos organizacionais de sobrevivência no 
ambiente social em que estão integradas (DiMaggio \& Powell, 1991; Greenwood et al., 2008; Scott, 2008a). Adicionalmente, a partir de uma noção processual, a legitimidade pode ser compreendida como "um conjunto estruturado ou conjuntos de atividades formais ou emergentes que descrevem como um ator adquire afiliação com uma ordem ou categoria social existente" (Suddaby, Bitektine \& Haack, 2017, p. 462). Essa leitura permite o entendimento da legitimidade enquanto componente construído e negociado socialmente, podendo ser identificado com base em três possibilidades: linguagem e comunicação, processos de teorização e ideias de identificação/categorização (Suddaby et al., 2017), sendo a primeira adotada neste estudo para a compreensão do fenômeno.

O processo de construção social da legitimidade pela via discursiva, portanto, comporta atenção a dois elementos: os legitimacy accounts e os frames. Os legitimacy accounts enquanto explicações, desculpas e justificativas utilizadas pelas organizações ou determinados atores para invocar (Ashforth \& Gibbs, 1990), ou mesmo manter a legitimidade organizacional (Sheridan \& Mote, 2017), são evidenciados em diversos estudos, tanto como recurso para o desenho metodológico de pesquisas, como enquanto elemento de expressão do debate no contexto interacional (Creed et al., 2002; Elsbach, 1994; Lamertz \& Baum, 1998; Sheridan \& Mote, 2017).

Já os processos de framing, elementos bastante utilizados na teoria dos movimentos sociais e que buscam a compreensão das "bases cognitivas para a ação coletiva" (Creed et al., 2002, p. 479), atuam sobre a compreensão de aspectos de mobilização e contramobilização de "ideias e significados" (Benford \& Snow, 2000, p. 613), podendo ser exemplificados por estudos que utilizam a estratégia de framing para a compreensão de temáticas como risco de inundações (Escobar \& Demeritt, 2014) e desaparecimento de idiomas (Rivenburgh, 2013). Importa salientar que ao mencionar framing, faz-se referência lógica de processo, já ao evocar frames, remete-se à noção de quadros ou emoldurações da realidade, aspecto sobre o qual este estudo foi, em grande medida, embasado.

Assim sendo, a articulação teórica que fundamenta a pesquisa em questão toma como base, em primeiro momento, a zona de intersecção entre o institucionalismo organizacional e os estudos sociolegais, na medida em que considera a dinâmica legal relacionada à reforma dos TCs enquanto espaço ambíguo, político e constituído e as organizações que a compõe como entes culturais que, ao responderem às demandas do campo, mobilizam o sentido legal. Em segundo momento, com o objetivo de estabelecer mecanismos teóricos de delimitação dos contornos do fenômeno, em especial os atores e ideias que mobilizam o discurso nas esferas legal, organizacional e social, utiliza-se a lógica de campo, organizacional e legal, bem como suas fronteiras de intersecção. Por fim, em um terceiro movimento, como forma de instrumentalizar o mergulho analítico sobre o componente discursivo do objeto de análise, optou-se pela utilização dos recursos de legitimacy accounts e framing.

\section{PROCEDIMENTOS METODOLÓGICOS}

O estudo apresentou delineamento em bases de caráter exploratório-descritivo, cunho qualitativo, horizonte temporal longitudinal e estratégia de estudo de caso (Saunders, Lewis \& Thornill, 2009). Adotou ainda nível de análise de campo organizacional, entendido como o conjunto de atores, legais e não legais, integrantes do debate em torno da reforma dos TCs no período 2000 a 2017, lapso justificado pela ampla presença de debates sobre a legitimidade dos TCs nos contornos do ano 2000. Como unidade de análise, delimitou-se os aspectos discursivos do próprio debate em torno da reforma. 
Com período de coleta entre agosto de 2017 e janeiro de 2018, a etapa de pesquisa documental foi constituída de 198 documentos com o intuito de investigar preliminarmente o campo. Os documentos foram segmentados da seguinte forma:

a. 50 documentos legislativos, sendo 40 projetos de emenda à constituição (PECs) ligados aos TCs, com suas respectivas exposições de motivos (entre 1995 e 2017), quatro vídeos de audiências públicas e seis discursos parlamentares ocorridos no âmbito de discussão das PECs 028/2007, 329/2013 e 302/2017 no Legislativo;

b. 23 documentos coletados de portais institucionais e páginas eletrônicas de movimentos sociais ligados à reforma dos TCs;

c. Quatro exposições sobre a temática, sendo três debates sobre a reforma dos TCs e uma sessão plenária no Supremo Tribunal Federal (STF) sobre o julgamento da extinção do Tribunal de Contas dos Municípios do Estado do Ceará;

d. 19 itens de comunicação escrita, sendo sete livros sobre os TCs e 12 revistas técnicas e associativas produzidas pelas corporações profissionais ligadas a essas organizações;

e. 31 documentos de eventos realizados pelas corporações profissionais do campo em discussão; e

f. 71 documentos oriundos da mídia, sendo 19 artigos de opinião, 48 matérias jornalísticas, uma reportagem e três entrevistas sobre os TCs.

A reunião dos documentos teve motivação exploratória e foi realizada de modo livre, sempre respeitando a pertinência temática com o assunto em discussão, no caso a reforma dos TCs, e as recomendações complementares de alguns entrevistados.

Já a etapa de entrevistas, conduzida no mesmo período mencionado, foi realizada com 21 indivíduos, em condução semiestruturada e com o suporte da técnica de bola de neve (Creswell, 2007), tendo como intuito a exploração da dinâmica de campo organizacional analisada, de modo a complementar as informações oriundas do quadro documental. O corpus de entrevistas totalizou $15 \mathrm{~h}$ e $22 \mathrm{~min}$ de gravação, representando duração média de 43 min para cada interlocução. Os entrevistados foram segmentados, apenas para efeito de posicionamento de aspectos discursivos, em cinco categorias de atores, legais e não legais, a saber: corporações profissionais, mídia, sociedade civil organizada, academia e judiciário. Os atores entrevistados foram selecionados com base no nível individual e organizacional de envolvimento e na inserção em relação ao debate em torno da reforma.

A análise dos dados se deu por meio da técnica de análise de conteúdo (Bardin, 2011), com o apoio do software de análise qualitativa $\mathrm{NVivo}^{\circledR}$. A análise foi estruturada em duas etapas:

1. A primeira selecionou, de modo livre, incidentes críticos (discursivos ou não) de natureza legal, gerencial e social no contexto dos dados primários e secundários reunidos; e

2. A segunda contextualizou os incidentes levantados em três diferentes frames, segundo as lógicas que os fundamentavam: legal, normativa e responsiva. Para o frame legal, foi considerado o agrupamento de incidentes ligados aos dispositivos legais formais e prescritivos e à noção de sentido e significado legal associada a esses instrumentos; para o frame normativo, considerou-se o agrupamento de incidentes cujos marcadores remetessem a aspectos práticos de influência sobre o comportamento organizacional dos TCs, mas que também destacassem recursos de ressignificação das práticas gerenciais e dos propósitos dessas organizações; por fim, oframe responsivo considerou 
o agrupamento de incidentes envolvendo ações e discursos ligados à visibilidade social dos TCs como forma de caracterizar extensão social do tema.

\section{MOBILIZAÇÃO EM TORNO DA REFORMA: OS FRAMES LEGAL, NORMATIVO E RESPONSIVO}

Esta seção foi dividida em duas partes. A primeira apresenta a mobilização discursiva em torno da reforma dos TCs, no período de 2000 a 2017, sob a ótica dos frames legal, normativo e responsivo. Já a segunda discute, com base nos resultados encontrados, as fronteiras de observação do fenômeno. Os frames delineados contribuem para a leitura contextual do fenômeno analisado a partir dos mecanismos de regulação, ressignificação e conformidade legal em torno dos TCs; dos elementos de ressignificação das práticas organizacionais, mediante a progressiva transição da gestão política para a revitalização da competência técnica dos TCs; e do progressivo aumento da visibilidade social dos TCs como marca de responsividade identificada ao longo do processo.

\subsection{Frame legal: regulação, ressignificação e conformidade legal dos TCs}

Sob a ótica do processo de mobilização associado à legalidade e à ressignificação legal, foi possível observar: 1. o histórico de propostas de positivação de regras legais por meio de PECs; 2 . as sinalizações de engajamento junto a instituições jurídicas e legislativas; e 3. a expressão da construção da legalidade e da ressignificação legal como elementos emergentes do debate a partir, em primeira instância, de uma nova forma de enxergar os TCs e, em segunda instância, de aspecto contextual voltado para o atendimento da expectativa de uma cultura legal brasileira detalhista.

1. No tocante às propostas de positivação de regras legais por meio de PECs, observou-se que, não obstante a discussão no plano das ideias, a crítica ao atual modelo dos TCs não permanece apenas na lógica do debate, tem sido também ofertada ao longo dos anos em sede do Poder Legislativo. Desse modo, ao se enumerar por assunto 40 PECs no período de 1995 a 2017, constatou-se que as temáticas circularam entre:

- A fixação de mandato e quantidade de membros dos TCs (cinco PECs);

- O aperfeiçoamento de competências (três PECs);

- Os critérios de nomeação e escolha de membros dos TCs (18 PECs);

- A extinção dos TCs (seis PECs);

- A forma de composição e criação de mecanismos de controle externo para os TCs (cinco PECs);

- A criação da auditoria de controle externo no âmbito dos TCs (uma PEC);

- O padrão nacional para o processo de controle externo (uma PEC); e

- A fixação dos TCs como órgãos permanentes (uma PEC).

As temáticas pautadas no âmbito do Legislativo, portanto, refletem em grande medida os núcleos de debate formatados nos últimos anos (Ramires \& Rocha, 2015; Rocha, 2002), sendo observado recentemente o deslocamento do debate em torno do questionamento da legitimidade dos TCs, de um polo associado à noção de extinção, para um ancoramento na noção de aperfeiçoamento dessas instituições. Nesse cenário, destacaram-se as discussões em torno de três PECs: 329/2013, 040/2016 
e 022/2017, que serão alvo da discussão a seguir considerando o prisma de engajamento jurídico e legislativo a elas associado.

2. No que se refere ao engajamento organizacional perante as instituições jurídicas e legislativas, constatou-se uma mobilização inicial ligada à contextualização do campo legislativo no tocante à efemeridade do debate eà ausência de interesse na discussão relacionada à reforma dos TCs, assim como a ausência de legitimidade como elemento associado ao risco legislativo, conforme trechos a seguir:

[...] os caras nunca mexeram, nem no momento mais crítico, quando prenderam o tribunal do Rio praticamente inteiro e começou a se discutir isso de novo [...] o Congresso não está interessado nisso. Não são textos que vão avançar (Entrevistado 15 - Mídia).

Hoje o momento do parlamento é anticontrole e fortalecer tecnicamente ainda mais os TCs seria perda de poder para eles (Entrevistado 12 - Corporações Profissionais).

Ainda no âmbito de movimentações no Legislativo, assim como no Judiciário, registra-se a contratação, por parte de uma das corporações profissionais ligadas aos TCs, de serviços de assessoria parlamentar e advocacia, sinalizando para uma estruturação das entidades do campo no que diz respeito à inserção legislativa e judicial organizada.

3. Na observação da construção da legalidade e da ressignificação legal como elementos emergentes do debate, foi possível observar a invocação de um continuum entre o polo técnico e o político, em grande medida ilustrado a partir da comparação dos TCs com os poderes Judiciário e Legislativo, como retrato da ressignificação do papel e da legalidade associada a essas instituições, conforme trecho a seguir:

Muito se fala: o TC é um órgão auxiliar do poder Legislativo, como se a gente tivesse ali para digitar alguns relatórios para o Legislativo e não é isso. O TC é uma instituição independente, que não depende do funcionamento do Legislativo, [...] o tribunal precisa se assemelhar ao Judiciário e não ao Legislativo, porque se ele funciona segundo as bases do Legislativo, ele não vai passar uma ideia para a sociedade de que faz o devido processo legal, longe das paixões que são típicas do Legislativo (Presidente de corporação profissional, Câmara dos Deputados, 2017).

Observou-se ainda, a invocação de valores e construções sociais, focando em aspectos culturais que remetem, sob a ótica dos entrevistados, a uma cultura legal detalhista e excessivamente positivada como fio condutor das discussões em torno da legalidade, conforme mostrado nos depoimentos a seguir:

Por certo não está na política a falha de comportamento daqueles que são escolhidos e sim talvez na sociedade; não existe uma sociedade, não existe um parlamento ou tribunais corruptos se a sociedade também não o for (Representante da Ordem dos Advogados do Brasil - OAB, Câmara dos Deputados, 2017).

É muito mais resposta para nossa cultura brasileira de um direito detalhado, de um direito que decorre do direito romano, em que os princípios e até regras expressas não são cumpridos (Entrevistado 03 - Corporações Profissionais). 
Em suma, o frame legal ordena os fatos analisados sob a ótica dos mecanismos de regulação, ressignificação e conformidade legal dos TCs. Assim, em que pese o fato de as PECs propostas não terem se efetuado na realidade legal prática, os registros trazem à tona os esforços de mobilização com viés prescricional e de conformação legal dos TCs, além de demarcarem discursivamente questões controversas ligadas à efetivação do papel constitucional eà melhoria dos mecanismos organizacionais e processuais dessas cortes, ancorando o debate legal em uma noção de TC mais próxima do Judiciário e menos assemelhada ao Legislativo.

\subsection{Frame normativo: da gestão política à competência técnica dos TCs}

Como um processo normativo associado à mudança de comportamento no nível interorganizacional, foi possível observar: 1. a ressignificação do papel das corporações profissionais, enquanto mecanismo agêntico que expressa a atuação de entidade coletiva interessada, em primeiro momento, na representação coletiva e, em segundo momento, na regulação do campo organizacional; e 2. o desenho e aplicação de mecanismos influenciadores de soft enforcement como o Programa de Modernização do Controle Externo dos Estados e Municípios Brasileiros (PROMOEX) e o Programa Qualidade e Agilidade nos TCs (QATC).

1. No tocante à ressignificação do papel das corporações profissionais, tem-se que as pautas propostas pelas corporações, no período de 2003 a 2017, evoluíram de um foco de atuação estritamente corporativo e de socialização entre associados, para uma interlocução direcionada ao aprimoramento dos TCs enquanto sistema. Nesse sentido, as temáticas afeitas a esse levantamento histórico consideraram diversas dimensões: seja no campo da representação simbólica e de formação de identidade organizacional, seja sobre aspectos estruturais e de mudança de comportamento organizacional, ou até mesmo sobre dimensões relacionais dos TCs e de atuação com base em instrumentos e deliberações das corporações profissionais.

Ao lado das questões mencionadas, aspectos discursivos sobre a ressignificação do papel das corporações profissionais foram identificados. Nesse sentido, as evidências demonstraram, sob uma primeira ótica, representação das corporações profissionais como organizações muito próximas do jogo político-corporativista, caracterizando-as a partir das rotinas de atividades de integração e socialização, conforme relatado adiante:

As associações nunca foram boas fontes, porque eu acho que elas fazem um ativismo muito próximo do jogo político e do corporativismo (Entrevistado 14 - Mídia).

Associação de classe mesmo, fazia festinha, encontrava, fazia convênios para ter desconto, discutia salário, algo assim. Nada relacionado ao sistema, tanto que pouca gente participava e não tinha expressividade (Entrevistado 11 - Corporações Profissionais).

Demonstraram também posições intermediárias de neutralidade, em que se verificou um papel de fiscalização e vigilância do sistema de controle externo, posicionamento pautado principalmente em função da ausência de efetividade de instrumentos formais de acompanhamento como, por exemplo, as corregedorias. 
"Então elas são bem importantes, fazem o lobby corporativo, mas funcionam também no papel de fiscalização das autoridades” (Entrevistado 15 - Mídia).

Sob outra ótica, foi possível evidenciar uma segunda visão sobre as corporações profissionais, dessa vez menos vinculada ao corporativismo funcional e mais ligada ao debate estrutural e propositivo sobre o sistema de controle externo.

Se elas se mostrarem como sendo entidades basicamente classistas, elas não terão apoio da sociedade. É preciso deixar bem claro que os nossos interesses não são meramente classistas, são interesses institucionais, por isso essa pauta comum, essa pauta de aperfeiçoamento do controle tende a ser melhor aceita pela sociedade (Entrevistado 07 - Corporações Profissionais).

\section{No que diz respeito ao desenho è̀ aplicação de mecanismos influenciadores de soft enforcement} a partir de programas como PROMOEX e o QATC, salienta-se que foi possível observar para o PROMOEX uma caracterização de origem exógena ao sistema dos TCs, muito embora posteriormente tenha recebido apoio institucional das entidades pertencentes ao campo. Observou-se ainda que, embora desenhado sob uma ótica de fomento à indução de aperfeiçoamento do sistema, a percepção do programa resultou, em grande medida, em um caráter de estruturação e de oferta de recursos para o sistema dos TCs, sem adentrar efetivamente em reformas sistêmicas e estruturais.

O PROMOEX foi coisa meio de cima para baixo. Foi iniciativa do Ministério do Orçamento e Gestão [...] não partiu do sistema de controle (Entrevistado 11 - Corporações Profissionais).

Ademais, em um segundo momento após o PROMOEX, foi possível observar a atuação da corporação profissional denominada ATRICON (Associação dos Membros dos Tribunais de Contas do Brasil) no âmbito do QATC, segmentado por duas frentes: uma de resoluções/diretrizes, por meio das quais a corporação faz recomendações aos TCs, e outra por intermédio do Marco de Medição de Desempenho dos TCs (MMD-TC), momento de avaliação dos TCs com base em critérios de performance preestabelecidos (Atricon, 2017a). Tal iniciativa surgiu, segundo percepções, como resposta organizacional ao contexto de críticas e contestações vivenciado pelos TCs.

Observou-se também o QATC enquanto principal ponto de reforço da ideia de ressignificação das corporações profissionais já que, decorrente do movimento de reorganização da atuação dos TCs voltado para o aprimoramento institucional, tal instrumento abriu nova frente de discussão no campo, fundada a partir das corporações, que em algumas ocasiões tiveram sua atuação comparada à que o $\mathrm{CNJ}$ adota para com o Poder Judiciário.

Antes ela atuava mais como associação de classe mesmo, corporativa, e hoje ela atua muito como um órgão semelhante ao CNJ. Então é um órgão que tem tentado ter influência na atuação dos TCs. Ela não pode obrigar, mas tem estimulado com o MMD-TC, com os índices de efetividade dos TCs, tem editado resoluções, por exemplo, voltadas a estimular e uniformizar as atuações (Entrevistado 01 - Academia).

Em sede do MMD-TC, algumas percepções emergiram como, em primeiro momento, as relacionadas às estratégias de manutenção e adesão da ferramenta pelo sistema de TCs, tais como 
a dispensa de ranqueamento e divulgação dos resultados obtidos pela ferramenta e, em segundo momento, as ligadas ao marco de medição enquanto instância de conhecimento e não, efetivamente, de atuação, principalmente em face da ausência de natureza impositiva e coercitiva. Ambas estão representadas nos depoimentos a seguir:

Foi um momento riquíssimo para enfrentar as nossas próprias mazelas. O que não é uniforme, vamos uniformizar, o que a gente não tem, vamos tentar buscar. Expondo, mas dentro do sistema. Só foi possível a adesão voluntária, porque não é ranqueado e porque não é exposto (Entrevistado 11 - Corporações Profissionais).

O marco de medição busca conhecer o sistema, no entanto, é preciso não só conhecer, mas reconhecer que é preciso mudar. Os marcos, eles nos permitem conhecer o sistema, mas na medida em que não são publicados, na medida em que não se leva em consideração os dados obtidos, não se permite o reconhecimento de deficiências [...] o marco é feito por uma entidade classista e ela não tem a força de impor comportamento (Entrevistado 07 - Corporações Profissionais).

Em síntese, o frame normativo aponta para esforço de ressignificação do papel e das práticas organizacionais mediante a transição da gestão política para a revitalização da competência técnica dos TCs. Nesse ponto, destaca-se o processo discursivo de ressignificação do papel das corporações profissionais, de um revestimento recreativo para a instrumentalização do debate técnico e de melhoria dos TCs e, como decorrência disso, a ressignificação das práticas de indução e avaliação de desempenho dos TCs, a exemplo do PROMOEX e QATC.

\subsection{Frame responsivo e a visibilidade social dos TCs}

Como um processo responsivo, associado à integração entre grupos das esferas política e jurídica, foi possível observar: 1. a inserção de grupos da sociedade civil organizada no debate, principalmente na segunda década analisada, ou seja, a partir de 2011; e 2. a identificação da centralidade do movimento de responsividade em torno da atuação das corporações profissionais.

1. No tocante à inserção, principalmente na segunda década analisada, ou seja, a partir de 2011, de grupos da sociedade civil organizada no debate, verificou-se movimentos associados à responsividade em torno do debate sobre a reforma dos TCs, como: campanhas de ministro e conselheiro cidadão, movimento pela democracia nos TCs, campanhas de conselheiro técnico, movimento pela mudança dos TCs, manifesto de juristas, entre outros.

As campanhas de ministro e conselheiro cidadão tiveram seu primeiro registro marcado por uma candidatura ao cargo de ministro do Tribunal de Contas da União (TCU) com base em uma sustentação de despolitização da corte, em 2011. A partir de então, espalhou-se por diversos estados e evoluiu para a disseminação da noção de que os TCs e seus cargos são espaços públicos de acesso à sociedade como um todo.

O conselheiro cidadão é uma proposta dentro do quadro normativo atual, você procura democratizar e qualificar a escolha do órgão político (Entrevistado 02 - Corporações Profissionais). 
Já a campanha de conselheiro técnico (Pessoa, 2017), traz noção de tecnicidade para a escolha, principalmente partindo das carreiras técnicas que compõem os TCs, de modo que o nome indicado e apoiado pela população tenha respaldo nos critérios definidos pela Constituição.

A campanha conselheiro técnico está centrada em arregimentar um técnico do controle externo para poder conduzir esse processo de eleição, diferente da campanha conselheiro cidadão, em que eu posso arregimentar alguém da sociedade, técnico ou não (Entrevistado 07 - Corporações Profissionais).

Sobre o movimento de juristas (Consultor Jurídico [Conjur], 2017; Conti, 2016, 2017), tal iniciativa surgiu em função de discussão sobre a constitucionalidade da fiscalização dos TCs pelo CNJ, de modo a viabilizar a construção e sustentação de um consenso mínimo sobre a juridicidade de determinados argumentos.

A ideia surgiu em um dos momentos em que uma das PECs estava sendo discutida [...] e o intuito foi tentar ter um consenso mínimo jurídico a respeito de um futuro modelo (Entrevistado 01 Academia).

O MUDATC, por sua vez, apresenta dinâmica mais abrangente, de modo a tentar, por intermédio das corporações profissionais, ampliar o debate sobre o aprimoramento dos TCs.

O MUDATC é um movimento das associações [...] e a gente tenta incorporar e fazer com que ele cresça, para que ele possa ser de toda sociedade, e se não for, não vai ter reforma nenhuma em TC. Se não for a sociedade querendo, querendo muito, não vai acontecer (Entrevistado 02 Corporações Profissionais).

\section{Em relação à identificação da centralidade do movimento de responsividade em torno da} atuação das corporações profissionais, registra-se que essa frente de ação parte, principalmente, da necessidade de infundir os TCs com valores sociais em meio a um contexto de desconhecimento e contestação social, já que as mobilizações vigentes, em grande medida, apresentam caracterização endógena ao sistema, com pouca repercussão social, conforme trechos relatados a seguir:

Um dos órgãos que são avaliados nas pesquisas que nós fazemos são os TCs, eles são os mais mal avaliados, há muito tempo. Os TCs são desconhecidos da população e você vê que não são efetivos (Entrevistado 21 - Sociedade Civil Organizada).

São movimentos que nascem dos próprios TCs, dos servidores, de representantes do Ministério Público, a população mesmo não aderiu. Se você olhar bem a $\mathrm{OAB}$ não aderiu completamente, os movimentos civis organizados não aderiram completamente, o cidadão pulverizado não aderiu completamente (Entrevistado 11 - Corporações Profissionais).

A partir de 2011, identificou-se a evolução da participação de movimentos sociais em torno do debate sobre a reforma dos TCs nos mais diversos aspectos, entre eles: apoio a candidaturas de cargos 
deliberativos ligados aos TCs; mobilização em torno da significação dos dispositivos legais ligados ao processo de escolha dos membros dos TCs; movimentos associados à ampliação da democratização e combate à corrupção nos TCs; movimentos associados à compreensão da legalidade, a despeito do movimento de juristas; dentre outros, sinalizando para indícios de ampliação da permeabilidade social do debate, conforme relatado a seguir:

Como você defende a não extinção de um TC que acaba de aprovar as contas de um prefeito com 140 ressalvas? Como você defende a existência de um TC como esse? E eu falei assim: se nós pegarmos lá atrás, antes da existência do TC [...] e passássemos pelos mesmos critérios de aferição dessas contas, de verificação, de auditoria, nós não encontraríamos 140 ressalvas, nós encontraríamos 140.000 ressalvas. A simples existência dos TCs já faz com que o ordenador de despesa, com que o gestor, na hora de colocar a assinatura dele no documento, pense duas vezes. Agora imagina então esse TC aprimorado, cumprindo com força e com eficácia o seu papel (Entrevistado 19 - Sociedade Civil Organizada).

Resumidamente, o frame responsivo delineia o espaço do debate sobre a reforma ligado à visibilidade social dos TCs. Esse contorno, emergente da fração política do debate, influenciou a realização das campanhas conselheiro técnico e cidadão, e o desenho de movimentos como o MUDATC, cujas extensões representam potencial agregador em nível de sociedade. Menciona-se ainda, como decorrente desta visão, o aspecto discursivo pendular, em primeiro instante, de contestação da legitimidade dos TCs pela via organizacional de politização da atuação e, em segundo momento, de defesa da relevância social dessas organizações pela via institucional, representada pelo capital reputacional derivado dos ordenamentos constitucional e social brasileiros.

\subsection{Legalidade, normatividade e responsividade: fronteiras de observação do fenômeno}

De posse dos frames de orientação legal, normativa e responsiva, esta seção objetivou discuti-los sob a ótica sistematizada, de modo a contemplar resgate teórico necessário, destacando que são visões diferentes, e não excludentes, para interpretação do mesmo fenômeno. Guia para a discussão proposta, o Quadro 1 apresenta os frames por tipo de reforma, agentes principais, papel dos atores, definição do problema, fonte do problema, nível de mobilização, solução do problema e cenário ideal.

\section{QUADRO 1 FRAMES LIGADOS AO PROCESSO DE MOBILIZAÇÃO EM TORNO DA REFORMA DOS TCS}

\begin{tabular}{cccc}
\hline Frame & Legal & Normativo & Responsivo \\
\hline Tipo de reforma & Legal & Comportamental & Social \\
Agentes principais & Corporações profissionais e & Corporações profissionais e & Corporações profissionais e \\
& agentes legais & agentes de gestão & agentes sociais \\
0 papel dos agentes & Mobilização junto a agentes do & Mobilização junto aos dirigentes & Mobilização junto à sociedade \\
\cline { 2 - 4 } & campo legal & dos TCs & civil organizada \\
\hline
\end{tabular}




\begin{tabular}{|c|c|c|c|}
\hline Frame & Legal & Normativo & Responsivo \\
\hline Definição do problema & $\begin{array}{c}\text { Um problema de conformação } \\
\text { legal }\end{array}$ & $\begin{array}{c}\text { Um problema de } \\
\text { comportamento organizacional }\end{array}$ & $\begin{array}{l}\text { Um problema de invisibilidade } \\
\text { social }\end{array}$ \\
\hline Fonte do problema & $\begin{array}{c}\text { Construção e ressignificação } \\
\text { legal }\end{array}$ & Comportamento político dos TCs & $\begin{array}{c}\text { Desconhecimento social sobre } \\
\text { os TCs }\end{array}$ \\
\hline Nível de mobilização & Legislativo e Judiciário & Instâncias de gestão dos TCs & Sociedade civil organizada \\
\hline Solução do problema & $\begin{array}{l}\text { Alteração de dispositivos e } \\
\text { ressignificação legal }\end{array}$ & $\begin{array}{c}\text { Alteração de comportamento } \\
\text { dos TCs, do político para o } \\
\text { técnico }\end{array}$ & $\begin{array}{c}\text { Convergência a valores societais } \\
\text { e maior participação social }\end{array}$ \\
\hline Cenário ideal & $\begin{array}{l}\text { TC legalmente } \\
\text { conforme }\end{array}$ & $\begin{array}{l}\text { TC organizacionalmente } \\
\text { legítimo }\end{array}$ & TC socialmente responsivo \\
\hline
\end{tabular}

Fonte: Elaborado pelos autores.

Sob a ótica da definição, na perspectiva legal o problema é visto como de reconstrução e ressignificação legal sendo, desse modo, mediado tanto pela proposição de dispositivos legais que enquadrem prescritivamente a realidade associada aos TCs, como pelo próprio reconhecimento e ressignificação social do discurso que mobiliza o debate em torno da proposição dessas regras. Nesta perspectiva, considera-se como cenário ideal a figura do TC legalmente conforme, cujas regras estão demarcadas por noção amplamente imbuída de valores societais. A proximidade de visão pode ser percebida com a teoria institucional-política (Talesh, 2009), que trata de incursões organizacionais sobre o espaço legal, principalmente por intermédio de interações com o Legislativo e, em certa medida, com o Judiciário. Para essa corrente, o valor legal socialmente produzido possibilita maior inserção na realidade social que, sendo culturalmente construída, adota o entendimento da lei enquanto "sistema de princípios morais, papéis roteirizados e símbolos sagrados" (Edelman \& Suchman, 1997, p. 482).

De modo empírico, os episódios ilustrados no frame legal sequenciam dinâmica material-cultural associada à legalidade. Ao abordar inicialmente o histórico de propostas de positivação de regras legais por meio de PECs, é possível depreender leitura não apenas de viés prescricional mas, sobretudo, ideacional do debate. Em seguida, ao tocar em questões relacionadas com o engajamento organizacional perante o campo legal, retratado pela interface com instituições jurídicas e legislativas, avança-se para a zona de contato entre os recortes organizacional-legal. Por último, ao se destacar elementos ligados ao desenho cultural sobre o qual se alicerça o debate legal, a exemplo do enquadramento discursivo de uma noção de TC mais próxima do Judiciário e menos assemelhada ao Legislativo ou mesmo pela invocação de expressões como "sentimento constitucional", revela-se o efeito social das fronteiras aqui debatidas.

$\mathrm{Na}$ perspectiva normativa, o problema é visto como sendo de base comportamental associado à dimensão organizacional, apresentando como via de solução para cenário ideal a imagem de um TC organizacionalmente legítimo, ou seja, predominantemente técnico em detrimento das investidas políticas. Nesse segundo enquadramento, nota-se a percepção de organização enquanto estrutura suportada por princípios afetos ao sistema social ao qual ela está inserida (Rossoni, 2016), elemento que remete à mobilização estratégica em nível de campo como mecanismo relevante para a sobrevivência ou mesmo manutenção da legitimidade organizacional desse grupo de organizações diante das diversas audiências identificadas. 
A leitura prática do frame normativo apresenta diálogo em dois sentidos. O primeiro possibilita o enquadramento das corporações profissionais em papel recreativo, mas também revela pontos de extensão ligados ao simbolismo das classes representadas e dos próprios TCs, retrato que, progressivamente, migrou para uma noção de tecnicidade e profissionalismo. Essa leitura, em segundo momento, é reforçada pelo desenho e aplicação de mecanismos influenciadores de soft enforcement, representados pelos programas PROMOEX e QATC que, embora construídos em contexto endógeno permeado pelas interferências do segmento de corporações profissionais, obtiveram adesão por parte do ordenamento burocrático estatal dos TCs como sinônimo de mimetismo e esforço em direção à mudança organizacional.

Já para a perspectiva responsiva, a leitura ofertada para o problema ganha contorno sob a ótica social, ou seja, relacionada com o simbolismo e com a infusão de valores societais oriundos da participação social no processo. Sob essa roupagem, os TCs seriam apresentados pela noção de ideal socialmente responsivo e, portanto, apresentariam valores construídos no âmbito societal, aproximando-se da conjugação de aspirações sociais e autoridade legal discutida por Kagan (2009). Dessa maneira, ao ampliar a extensão de alcance dos demais frames, a dinâmica responsiva envolve maior diversidade de atores no debate.

O efeito prático do frame responsivo denota movimento de ampliação da participação social no debate. Exemplos dessa constatação estão nas campanhas conselheiro técnico e cidadão, cuja extensão social já era percebida, e em movimentos como o MUDATC. Ademais, menciona-se o movimento pendular de contestação da legitimidade e, ao mesmo tempo, reforço do papel institucional dessas organizações. Em outras palavras, se no plano organizacional existem falhas que merecem ser discutidas no tocante ao desenho de críticas e proposições de melhoria, no plano institucional, o papel dessas organizações diante do ordenamento jurídico e estatal brasileiro mantém contornos sociais de relevo, sentido e importância.

\section{CONCLUSÃO}

Ao buscar compreender a natureza político-discursiva do processo de mobilização em torno do debate sobre a reforma dos TCs, este estudo identificou três frames: legal, associado à regulação, ressignificação e conformidade legal dos TCs; normativo, associado à transição da gestão política à competência técnica dos TCs e; responsivo, associado à visibilidade social dos TCs. Esses achados possibilitam extensões em torno das interfaces de entendimento da "lei dos livros" e da "lei na prática", sinalizando para espaço de construção social, a partir de atuação determinados atores, presente no processo analisado. Reforçam também o componente da legitimidade organizacional enquanto mecanismo ligado à sobrevivência e enquadramento social das organizações no meio social ao qual pertencem. Ademais, possibilitam reflexão sobre o elemento da responsividade em organizações, na medida em que demonstram organizações mobilizadas, a partir de atores e discurso, para ampliar o alcance e reforçar aspectos legitimadores de sua atuação.

No que se refere às lições sobre o processo de reforma dos TCs, ao se olhar para os frames destacados, percebe-se que, embora o processo de mudança institucional ainda esteja em curso e sob construção, já é possível notar perspectiva discursiva de consolidação de sentido nas estruturas legais, organizacionais e sociais que alicerçam a realidade analisada. Na referida visão, destaca-se o papel estratégico das corporações profissionais como elos na mobilização de sentido associado às três 
perspectivas. Chama-se atenção ainda para a importância de intervenções gerenciais e políticas na realidade objetiva que considerem a conjugação das três esferas (legal, normativa e responsiva) como forma efetiva de produção de efeitos sociais sobre a legitimidade dos TCs, sob pena de incompletude e de dissociação entre os lastros legal, organizacional e social.

Como limitações de pesquisa, menciona-se o aparente desequilíbrio das vozes ouvidas no estudo, com proeminência das corporações profissionais, fato que, embora não tenha afetado os achados do estudo, foi minimizado pelo processo de triangulação de fontes e informantes. Cita-se também o recorte temporal do estudo que, uma vez ampliado, viabilizaria, por exemplo, a consideração de fatores críticos localizados no período anterior a 2000 e posterior à aprovação da $\mathrm{CF} / 88$, lacuna que aparentou conter importantes elementos para análises futuras, principalmente diante das diversas investidas sobre a necessidade de reforma e extinção dos TCs. Por fim, faz-se menção à possibilidade de aprofundamento analítico dos frames discutidos, sugestão que, embora não tenha sido objeto neste estudo, pode complementar o entendimento acerca do processo de mudança institucional analisado, sobretudo no tocante ao papel estratégico e transversal das corporações profissionais.

Como agenda a ser explorada futuramente a partir dos achados deste estudo, menciona-se, por exemplo, oportunidade de aprofundamento analítico dos frames - legal, normativo e responsivo - em direção à compreensão da mudança institucional em curso, à identificação mais precisa dos atores constituintes do referido campo e à demarcação de potenciais extensões que venham a auxiliar no entendimento da legitimidade dos TCs. Desse modo, pontos residuais poderiam ser melhor explorados como, no âmbito do frame legal, a expansão de competências e de atribuições dos TCs decorrentes do mandato ampliado pela $\mathrm{CF} / 88$, enquanto cenário de ambiguidade legal e de elaboração de esquemas ideacionais e disputas narrativas; no âmbito do frame normativo, a identificação de mecanismos de decoupling, inovação organizacional e mimetismo institucional em torno da aplicação de ferramentas como o MMD-TC e; no âmbito do frame responsivo, o processo de construção da relevância social dos TCs frente a noções socialmente difundidas de, dentre outras, "politização do controle", "excesso de controle" e "apagão de canetas".

Por fim, faz-se oportuno também o aprofundamento de discussão sobre o problema de agência associado ao papel das corporações profissionais ligadas aos TCs - a exemplo das que representam os Conselheiros, Conselheiros-Substitutos, Auditores de Controle Externo e Procuradores de Contas - já que a identificação de intermediários no contexto de mobilização de ideias constitui-se como ponto fundamental para a compreensão de esquemas de sustentação de ordens técnico-políticas que abrigam mecanismos de manutenção ou mudança em ordens institucionais. Além do mais, observou-se que esses atores apresentaram importante papel como constituintes inseridos no processo de mobilização de ideias e construção da legitimidade dos TCs e que, para além do desenvolvimento do próprio debate em torno da reforma e dos próprios TCs, também se verificou a evolução organizacional e a burocratização dessas organizações como forma de maior inserção e influência sobre a dinâmica de campo e, consequentemente, sobre o domínio de aprimoramento das cortes de contas. 


\section{REFERÊNCIAS}

Abraham, M. (2016, outubro 06). Os tribunais de contas e o poder cautelar de indisponibilidade de bens. Recuperado de https://www.jota.info/ opiniao-e-analise/colunas/coluna-fiscal/colunafiscal-os-tribunais-de-contas-e-o-poder-cautelarde-indisponibilidade-de-bens-06102016

Arantes, R. B., Abrucio, F. L., \& Teixeira, M. A. C. (2005). A imagem dos Tribunais de Contas subnacionais. Revista do Serviço Público, 56(1), 57 83. Recuperado de https://doi.org/10.21874/rsp. v56i1.217

Araújo, P. (2017, setembro 14). STF determina afastamento de 5 conselheiros do TCE-MT citados por ex-governador em delação. Recuperado de https:// g1.globo.com/mato-grosso/noticia/stf-determinaafastamento-de-5-conselheiros-do-tce-mt-citadospor-ex-governador-em-delacao.ghtml

Ashforth, B. E., \& Gibbs, B. W. (1990). The doubleedge of organizational legitimation. Organization Science, 1(2), 177-194. Recuperado de https://doi. org/10.1287/orsc.1.2.177

Atricon. (2017a). Qualidade e agilidade dos Tribunais de Contas: diretrizes e marco de medição de desempenho. Brasília, DF: Autor.

Atricon. (2017b). Revista Atricon Gestões 2014-2015 e 2016-2017. Recuperado de http://www.atricon.org. br/wp-content/uploads/2017/11/PDF_REVISTAATRICON_2017.pdf

Azevedo, R. R., \& Lino, A. F. (2018). O Distanciamento entre as Normas de Auditoria e as Práticas nos Tribunais de Contas. Sociedade, Contabilidade e Gestão, 13(2), 9-27. Recuperado de http://dx.doi. org/10.21446/scg_ufrj.v13i2.13665

Bardin, L. (2011). Análise de conteúdo. São Paulo, SP: Edições 70.

Benford, R. D., \& Snow, D. A. (2000). Framing Processes and Social Movements: An Overview and Assessment. Annual Review of Sociology, 26, 611-639. Recuperado de https://www.jstor.org/stable/223459

Câmara dos Deputados. (2017). Audiência Pública PEC 329/2017. Recuperado de https://www.youtube. com/watch?v=XbaMTS09Rr8

Consultor Jurídico. (2017, abril 11). Em manifesto, docentes cobram mudanças em modelo de tribunais de Contas. Recuperado de https://www.conjur.com. br/2017-abr-11/professores-assinam-manifestomodelo-tribunais-contas

Conti, J. M. (2016, julho 26). "PEC do padrão mínimo" vai aperfeiçoar tribunais de contas. Recuperada de https://www.conjur.com.br/2016-jul-26/contasvista-pec-padrao-minimo-aperfeicoar-tribunaiscontas

Conti, J. M. (2017). Moralização da administração pública: chegou a vez dos tribunais de Contas. Recuperado de https://www.conjur.com.br/2017abr-04/contas-vista-moralizacao-administracaopublica-vez-tribunais-contas

Creed, W. E. D., Maureen, A. S., \& Austin, J. R. (2002). Clothes Make the Person? The tailoring of legitimating accounts and the social construction of identify. Organization Science, 13(5), 475496. Recuperado de https://doi.org/10.1287/ orsc.13.5.475.7814

Creswell, J. W. (2007). Qualitative inquiry and research design: Choosing among five traditions (2a- ed.). Thousand Oaks, CA: Sage.

DiMaggio, P. J., \& Powell, W. W. (1983). The iron cage revisited: Institutional isomorphism and collective rationality in organizational fields. American Sociological Review, 48(2), 147-160. Recuperado de https://www.jstor.org/stable/2095101

DiMaggio, P. J., \& Powell, W. W. (1991). Introduction. In P. J. DiMaggio, \& W. W. Powell (Eds.), The new institutionalism in organizational analysis (pp. 1-38). Chicago, IL: The University of Chicago Press.

Edelman, L. B. (1992). Legal Ambiguity and Symbolic Structures: organizational Mediation of Civil Rights law. American Journal of Sociology, 97(6), 1531-1576. Recuperado de https://www.jstor. org/stable/2781548

Edelman, L. B. (2016). The Interplay of Law and Organizations. In L. B. Edelman (Ed.), Working law: courts, corporations, and symbolic civil rights (pp. 1-337). Chicago, IL: The University of Chicago Press.

Edelman, L. B., Fuller, S. R., \& Mara-Drita, I. (2001). Diversity rhetoric and the managerialization of law. American Journal of Sociology, 10(6), 1589-1641. Recuperado de https://doi.org/10.1086/321303 
Edelman, L. B., Krieger, L. H., Eliason, S. R., Albiston, C. R., \& Mellema, V. (2011). When Organizations Rule: Judicial Deference to Institutionalized Employment Structures. American Journal of Sociology, 117(3), 888-954. Recuperado de https:// www.jstor.org/stable/10.1086/661984

Edelman, L. B., Leachman, G., \& McAdam, D. (2010). On Law, Organizations, and Social Movements. Annual Review of Law and Social Science, 6, 653-685. Recuperado de https://doi.org/10.1146/annurevlawsocsci-102209-152842

Edelman, L. B., \& Suchman, M. C. (1997). The legal environments of organizations. Annual Review of Sociology, 23, 479-515. Recuperado de https://www. jstor.org/stable/2952561

Elsbach, K. D. (1994). Managing Organizational Legitimacy in the California Cattle Industry: The Construction and Effectiveness of Verbal Accounts. Administrative Science Quarterly, 39(1), 57-88. Recuperado de https://doi.org/10.2307/2393494

Escobar, M. P., \& Demeritt, D. (2014). Flooding and the framing of risk in British broadsheets, 1985-2010. Public Understanding of Science, 23(4), 454-471. Recuperado de https://doi. org/10.1177/0963662512457613

G1. (2017, março 29). Operação Quinto do Ouro nasceu de delações. Recuperado de https://g1.globo. com/rio-de-janeiro/noticia/operacao-quintodo-ouro-nasceu-de-delacao-de-ex-diretor-daodebrecht.ghtml

G1 CE. (2017a, agosto 08). Assembleia Legislativa do Ceará aprova extinção do Tribunal de Contas dos Municípios. Recuperado de https://g1.globo. $\mathrm{com} / \mathrm{ceara} /$ noticia/assembleia-legislativa-doceara-aprova-extincao-do-tribunal-de-contas-dosmunicipios.ghtml

G1 CE. (2017b, outubro 26). STF mantém extinção do Tribunal de Contas dos Municípios do Ceará. Recuperado de https://g1.globo.com/ceara/noticia/ stf-mantem-extincao-do-tribunal-de-contas-dosmunicipios-do-ceara.ghtml

Greenwood, R., Oliver, C., Sahlin, K., \& Suddaby, R. (2008). The Sage handbook of organizational institutionalism. Thousand Oaks, CA: Sage.

Guarido, E. R., Filho, Luz, B. B. C., \& Silveira, T. R. (2018). Legitimidade organizacional no contexto de organizações da justiça. In Anais do Encontro de Administração da Justiça 2018, Brasília, DF.

Guimaraes, T. A., Gomes, A. O., \& Guarido, E. R., Filho. (2018). Administration of justice: an emerging research field. RAUSP Management Journal, 53(3), 476-482. Recuperado de https://doi.org/10.1108/ RAUSP-04-2018-010

Kagan, R. A. (2009). Introduction to the Transaction edition. In P. Nonet, \& P. Selznick (Eds.), Law and society in transition: toward a responsive law (2nd ed., pp. vii-xxvi). Piscataway, NJ: Transaction Publishers.

Kluttz, D. N., \& Fligstein, N. (2016). Varieties of Sociological Field Theory. In S. Abrutyn (Ed.), Handbook of Contemporary Sociological Theory (pp. 185-204). New York, NY: Springer.

Lamertz, K., \& Baum, J. A. C. (1998). The Legitimacy ofOrganizational Downsizing in Canada: An Analysis of Explanatory Media Accounts. Canadian Journal of Administrative Sciences, 15(1), 93-107. Recuperado de https://doi.org/10.1111/j.1936-4490.1998. tb00154.x

Lino, A. F., \& Aquino, A. C. B. (2018). A Diversidade dos Tribunais de Contas Regionais na Auditoria de Governos. Revista Contabilidade \& Finanças, 29(76), 26-40. Recuperado de http://dx.doi. org/10.1590/1808-057x201803640

Lino, A. F., \& Aquino, A. C. B. (2020). Práticas não adequadas nos tribunais de contas. Revista de Administração Pública, 54(2), 220-242. Recuperado de https://doi.org/10.1590/0034-761220190270

Loureiro, M. R., Teixeira, M. A. C., \& Moraes, T. C. (2009). Democratização e reforma do Estado: o desenvolvimento institucional dos tribunais de contas no Brasil recente. Revista de Administração Pública, 43(4), 739-772. Recuperado de https://doi. org/10.1590/S0034-76122009000400002

Luz, B. B. C., Sousa, M. M., \& Guarido, E. R., Filho. (2019). Legitimacy Accounts no Debate sobre a Reforma dos Tribunais de Contas Brasileiros. Revista de Administração Contemporânea, 23(3), 311-330. Recuperado de http://doi.org/10.1590/19827849rac2019180300

Muda TCE-RJ. (2017). Lançamento da campanha Muda TCE-RJ. Recuperado de https://www.youtube. $\mathrm{com} / \mathrm{watch} ? \mathrm{v}=\mathrm{ph}-\mathrm{IZvXOy} 4 \mathrm{w}$ 
O Globo. (2017, março 30). Estados com problemas nos Tribunais de Contas. Recuperado de https:// oglobo.globo.com/brasil/estados-com-problemasnos-tribunais-de-contas-21134076

Oliveira, O. C. (2008). Diante do princípio federativo, seria constitucional uma lei nacional de processo dos tribunais de contas? Revista do Tribunal de Contas da União, 40(113), 13-32. Recuparado de https://revista. tcu.gov.br/ojs/index.php/RTCU/article/view/362

Pessoa, J. G. P. (2017, maio 12). A opção pelo Conselheiro Técnico. Recuperado de https://www. jota.info/opiniao-e-analise/artigos/a-opcao-peloconselheiro-tecnico-12052017

Ramires, C. C., \& Rocha, O. G., Neto. (2015). A reforma dos Tribunais de Contas: uma revisão a partir das propostas de emendas constitucionais. Revista Eletrônica Direito e Política, 10(2), 11841214. Recuperado de https://doi.org/10.14210/rdp. v10n2.p1184-1214

Rivenburgh, N. K. (2013). Media framing of complex issues: The case of endangered languages. Public Understanding of Science, 22(6), 704-717. Recuperado de https://doi.org/10.1177/0963662511426033

Rocha, A. C.(2013). A realização da accountability em pareceres prévios do Tribunal de Contas de Santa Catarina. Revista de Administração Pública, 47(4), 901-925. Recuperado de https://doi.org/10.1590/ S0034-76122013000400005

Rocha, C. A. A. (2002). O modelo de controle externo exercido pelos tribunais de contas e as proposições legislativas sobre o tema. Brasília, DF: Senado Federal. Recuperado de http://www2.senado.leg.br/ bdsf/item/id/156

Rocha, D., Zuccollotto, R., \& Teixeira, M. (2020). Insulados e não democráticos: a (im)possibilidade do exercício da social accountability nos Tribunais de Contas brasileiros. Revista de Administração Pública, 54(2), 201-219. Recuperado de https://doi. org/10.1590/0034-761220190294

Rossoni, L. (2016). O que é legitimidade organizacional? Organizações \& Sociedade, 23(76), 110-129. Recuperado de https://doi. org/10.1590/1984-9230766
Saunders, M., Lewis., P., \& Thornill, A. (2009). Formulating the research design. In M. Saunders, P. Lewis, \& A. Thornill (Eds.), Research Methods for Business Students (5. ed., Cap. 5). Harlow, UK: Pearson Education.

Scott, W. R. (1994). Law and Organizations. In S. B. Sitkin, \& R. J. Bies (Eds.), The legalistic organization (pp. 3-18). Thousand Oaks, CA: Sage Publications.

Scott, W. R. (2008). Institutions and Organizations: ideas and interests. Los Angeles, CA: Sage Publications.

Sheridan, M. J., \& Mote, J. E. (2017). Tracing legitimating accounts during times of change: the case of the organic food certification debate, 1990 to 2011. Organization \& Environment, 31(4), 360-383. Recuperado de https://doi. org/10.1177/1086026617706697

Speck, B. W. (2000). Inovação e Rotina no Tribunal de Contas da União. O Papel da Instituição Superior de Controle Financeiro no Sistema PolíticoAdministrativo do Brasil. Adenauer, 2000. São Paulo, SP: Fundação Konrad.

Suchman, M. C. (1995). Managing legitimacy: Strategic and Institutional approaches. The Academy of Management Review, 20(3), 571-610. Recuperado de https://www.jstor.org/stable/258788

Suddaby, R., Bitektine, A., \& Haack, P. (2017). Legitimacy. Academy of Management Annals, 11(1), 451-478. Recuperado de https://doi.org/10.5465/ annals.2015.0101

Talesh, S. A. (2009). The Privatization of Public Legal Rights: How Manufacturers Construct the Meaning of Consumer Law. Law \& Society Review, 43(3), 527562. Recuperado de https://doi.org/10.1111/j.15405893.2009.00381.x

Viana, I. S. (2017, abril 06). Tribunais de contas necessitam de aperfeiçoamento. Recuperado de https://www.conjur.com.br/2017-abr-06/ismarviana-tribunais-contas-necessitam-aperfeicoamento

Willeman, M. M. (2017). Accountability democrática e o desenho institucional dos Tribunais de Contas do Brasil. Belo Horizonte, MG: Fórum. 


\section{Bruno Batista de Carvalho Luz}

https://orcid.org/0000-0002-0066-0995

Doutorando em Administração pela Universidade de Brasília (UNB); Mestre em Administração pela Universidade Federal de Goiás (UFG); Auditor de Controle Externo no Tribunal de Contas do Estado de Goiás (TCE-GO). E-mail: brunobdcl@gmail.com

\section{Edson Ronaldo Guarido Filho}

https://orcid.org/0000-0001-7905-1596

Doutor em Administração pela Universidade Federal do Paraná (UFPR); Professor dos Programas de Pós-graduação em Administração da Universidade de Brasília (PPGA/UnB) e da Universidade Positivo (PPGA/UP); Professor do Programa de Pós-graduação em Gestão da Informação da Universidade Federal do Paraná (PPGGI/UFPR). E-mail: edson.guarido@gmail.com

\section{Marcos de Moraes Sousa}

http://orcid.org/0000-0002-0901-0550

Doutor em Administração pela Universidade de Brasília (UnB); Professor no Instituto Federal Goiano, Campus Ceres (IFGoiano); Professor permanente no Programa de Pós-graduação em Administração da Universidade Federal de Goias (PPGADM-UFG); Professor permanente no Programa de Pós-graduação em Educação Profissional e Tecnológica (ProfEPT-IFGOIANO). E-mail: marcos.moraes@ifgoiano.edu.br 